\title{
CORRESPONDENCE
}

\section{ATROPINE IRRITATION}

\section{To the Editors of THE BRITISH JouRnal OF OPHTHALMOLOGY.}

SIRS,-I have read with great interest the account of the thorough investigation of atropine irritation published in the Transactions of the Ophthalmological Society-Part I-1937.

In Southern Australia 1 per cent. atropine solutions are freely used as a matter of routine in adults and atropine irritation is not common, though I think more often seen where 2 per cent. atropine ointment is employed. When irritation does occur and a mydriatic is essential I have found scopolamine $\frac{1}{4}$ to $\frac{1}{2}$ per cent. effective and have not seen irritation follow its use.

But the discussion brought to mind the considerable reactions which I have seen following the use of cocaine especially in elderly people. One patient had so marked an idiosyncracy that one drop of a 5 per cent. solution of cocaine hydrochlor. dropped into the conjunctival sac caused almost serious illness of a week's duration. Blebs formed on the skin of the face and neck and violent conjunctivitis ensued. I have seen several milder cases, troublesome enough in all conscience, but all controllable by zinc sulphate solution $\frac{1}{4}$ per cent. which seems to be the remedy for all these curious manifestations.

It is rather remarkable that the injection of atropine into the conjunctiva, so frequently practised to obtain extreme mydriasis in iritic conditions, has in my experience so far never caused these curious reactions.

As regards atropine the position is so often reached that mydriasis is essential and so far the use of scopolamine has solved the difficulty. Though reference is made to its toxic action I have used the $\frac{1}{2}$ per cent. solution up to four times in the 24 hours and notwithstanding careful observations no toxic results have been apparent. I have, however, never used it in the form of ointment.

Whilst writing may I put a question to which an answer seems difficult, though Dr. Lockhart Gibson has made a suggestion. Salts, especially chlorides, seem able to enter the eye through the centre of the cornea; with animals' eyes this can be easily demonstrated. A solution of atropine 1 in 50 million parts will affect the iris. But how does the atropine act and almost instantaneously in the sub-conjunctival injection?

$$
\text { I am, etc., }
$$

JAMES W. BARRETt.

101-103, Collins STREet,

MELBOURNe, C1.

February 2, 1938. 